\title{
Early intervention services, cognitive-behavioural therapy and family intervention in early psychosis: systematic review
}

\author{
V. Bird, P. Premkumar, T. Kendall, C. Whittington, J. Mitchell and E. Kuipers
}

\section{Background}

Early intervention services for psychosis aim to detect emergent symptoms, reduce the duration of untreated psychosis, and improve access to effective treatments.

\section{Aims}

To evaluate the effectiveness of early intervention services, cognitive-behavioural therapy (CBT) and family intervention in early psychosis.

\section{Method}

Systematic review and meta-analysis of randomised controlled trials of early intervention services, CBT and family intervention for people with early psychosis.

\section{Results}

Early intervention services reduced hospital admission, relapse rates and symptom severity, and improved access to and engagement with treatment. Used alone, family intervention reduced relapse and hospital admission rates, whereas CBT reduced the severity of symptoms with little impact on relapse or hospital admission.

\section{Conclusions}

For people with early psychosis, early intervention services appear to have clinically important benefits over standard care. Including CBT and family intervention within the service may contribute to improved outcomes in this critical period. The longer-term benefits of this approach and its component treatments for people with early and established psychosis need further research.

\section{Declaration of interest}

None.
Early intervention services have been developed to address the needs of individuals with early psychosis. Typically, there is a delay between the onset of the first episode of psychosis and receiving an effective treatment - a period of untreated psychosis. ${ }^{1}$ Reducing this duration of untreated psychosis (DUP) for people with schizophrenia may lead to an improved prognosis. ${ }^{1-4}$ Early intervention services aim to detect emergent symptoms, reduce DUP, and improve early access to effective treatment, particularly in the 'critical period' (the first 3-5 years following onset). ${ }^{5-7}$ Although at the time there was little evidence for the effectiveness of this approach, early intervention services were developed in Australia, the USA, Canada, New Zealand and elsewhere; and the widespread deployment of such services was recommended in the National Service Framework for Mental Health ${ }^{8}$ and in the National Institute for Health and Clinical Excellence (NICE) guideline on schizophrenia for England and Wales. ${ }^{9}$

Since then, the provision of early intervention services has steadily increased, ${ }^{10}$ with 145 early intervention services currently operating in the UK, serving about 15750 individuals (Care Services Improvement Partnership, personal communication, 2009). Early intervention teams have also gradually evolved and now often consist of community-based multidisciplinary mental health teams that provide a combination of pharmacotherapy, family intervention, cognitive-behavioural therapy (CBT), social skills training, problem-solving skills training, crisis management and case management. ${ }^{11,12}$ However, although the evidence base for early intervention services is growing, their specific benefits have not been clearly demonstrated. ${ }^{13,14}$ Therefore as part of an update of the NICE guideline on schizophrenia, ${ }^{9,15}$ we conducted a systematic review of early intervention services for people with a first or early episode of psychosis. Because early intervention services typically include an individually tailored combination of evidence-based psychological interventions, we also examined the data on the separate use of CBT and family intervention used specifically in the context of early psychosis.

\section{Method}

\section{Search strategy and selection criteria}

We identified randomised controlled trials (RCTs) of early intervention services, CBT or family intervention for people with early psychosis, using the original schizophrenia guideline ${ }^{9}$ and five bibliographic databases (CINAHL, CENTRAL, EMBASE, MEDLINE, PsycINFO). The database search was conducted in September 2009 and restricted to English language papers or papers with an abstract in English. Full details of the search strategy can be found in the online supplement. Additional papers were identified by searching the reference list of retrieved articles, tables of contents of relevant journals, recent systematic reviews and meta-analyses of interventions in schizophrenia, and suggestions made by members of the schizophrenia Guideline Development Group (a comprehensive review protocol can be found in the updated edition of the full schizophrenia guideline, available from www.nccmh.org.uk). ${ }^{15}$

Early psychosis was defined as a clinical diagnosis of psychosis within 5 years of the first psychotic episode or presentation to mental health services. Interventions addressing high-risk groups or 'pre-psychotic'/prodromal populations were excluded, as were studies where the main focus of the intervention was not on psychosis or where the duration since the first psychotic episode was greater than 5 years.

\section{Quality assessment}

All trials meeting the eligibility criteria were assessed for methodological quality using a modified version of the SIGN checklist. ${ }^{16}$ Trials that were judged to be of adequate quality were included in the review. Trials that were not clearly described as randomised were excluded as were those with fewer than ten participants per intervention arm. 


\section{Data extraction}

Two of the authors (V.B. and J.M.) entered study details into a database and assessed methodological quality. Three of the authors (V.B., C.W. and P.P.) extracted outcome data into Review Manager (RevMan version 5.0.18 for Windows XP; The Cochrane Collaboration, Oxford, UK). The assessment of study quality and all outcome data were double-checked by one author (C.W.) for accuracy, with disagreements resolved by discussion.

Where available, data were extracted for the following outcomes: hospital admission; psychotic relapse (if appropriate criteria were used); DUP; and mean positive and negative symptoms as measured using the Positive and Negative Syndrome Scale (PANSS), ${ }^{17}$ Brief Psychiatric Rating Scale (BPRS), ${ }^{18}$ Scale for the Assessment of Positive Symptoms (SAPS) ${ }^{19}$ and the Scale for the Assessment of Negative Symptoms (SANS).$^{20}$ Outcome data were extracted at both end of treatment and follow-up (based on mean end-point scores). In light of the fundamental aims of early intervention services, ${ }^{12}$ data on remaining in contact with services and accessing psychosocial treatments were also extracted.

\section{Statistical analysis}

Meta-analysis was used, where appropriate, to synthesise the evidence using RevMan. Where possible, intention-to-treat with last observation carried forward data were used in the analyses. For binary outcomes, this approach assumes that participants leaving the study early, for whatever reason, had an unfavourable outcome. We calculated the standardised mean difference (SMD) for continuous outcomes, and relative risk (RR) for binary outcomes. For consistency, data from all outcomes (continuous and binary) were entered into RevMan in such a way that negative effect sizes or relative risks less than one favoured the active intervention. The number needed to treat for benefit $(\mathrm{NNTB})^{21}$ was calculated for statistically significant relative risks. Data from more than one study were pooled using a random-effects model, regardless of heterogeneity between trials, as this has recently been shown to be the most appropriate model in most circumstances. ${ }^{22}$ Summary effects were assessed for clinical importance, taking into account both the point estimate and the associated 95\% confidence interval $(\mathrm{CI})$.

\section{Results}

The search process and total number of trials included in the review are illustrated in Fig. 1. Details of all included trials can be found in Table 1, with further information about included and excluded studies available in online Tables DS1 and DS2.

\section{Early intervention services}

Four published trials $(n=800)$ were included in the meta-analysis of early intervention services: COAST (Croydon Outreach and Assertive Support Team); ${ }^{23}$ LEO (Lambeth Early Onset) ${ }^{11}$ the OPUS trial; ${ }^{24}$ and OTP (Optimal Treatment Project). ${ }^{12}$ Inspection of the Cochrane review of early interventions in psychosis ${ }^{13}$ identified three additional trials; however, these were excluded as they failed to meet our inclusion criteria regarding the population studied and comparison used. All included trials recruited participants from local mental health services such as community mental health teams, in-patient and out-patient services. However, the trials varied as to whether the participant was a new referral, with $\mathrm{LEO}^{11}$ including only those making contact for the first or second time, whereas COAST, ${ }^{23}$ OPUS $^{24}$ and $\mathrm{OTP}^{12}$ considered people who had a documented first contact within a specified time period, ranging from 12 weeks to 5 years.
Interventions often included a case manager or care coordinator, with a lower case-load than in standard care. In addition to medication management, all participants allocated to early intervention services were offered a range of psychosocial interventions, including $\mathrm{CBT},{ }^{11,12,23}$ social skills training ${ }^{24}$ and family intervention ${ }^{12,23,24}$ or family counselling, ${ }^{11}$ and vocational strategies such as supported employment. ${ }^{11,12,23}$ The psychosocial and vocational interventions were usually adapted to the needs of first-episode psychosis and offered on an 'as-required' basis. The frequency and duration of contact differed between trials, with the duration of the intervention lasting up to 2 years. Outcomes were reported at 9 months to 5 years post-randomisation.

Participants receiving early intervention services, when compared with those receiving standard care, were less likely to relapse $(35.2 \%$ v. $51.9 \%$; NNTB for one extra patient to avoid relapse $6,95 \%$ CI 3 to 25 ; heterogeneity $I^{2}=0 \%, P=0.67$ ) or be admitted to hospital $(28.1 \%$ v. $42.1 \%$; NNTB $=7,95 \%$ CI 5 to 7; heterogeneity $I^{2}=0 \%, P=1.00$ ) (Table 2). Early intervention services also significantly reduced positive symptoms with a pooled SMD of -0.21 ( $95 \%$ CI -0.42 to -0.01 ; heterogeneity $\left.I^{2}=9 \%, P=0.29\right)$ and negative symptoms with a pooled SMD of -0.39 (95\% CI -0.57 to -0.20 ; heterogeneity $I^{2}=0 \%$, $P=0.38$ ). The rate of discontinuation for any reason was lower for early intervention services compared with standard care $(27.0 \%$ v. $40.5 \%$; $\mathrm{NNTB}=8,95 \%$ CI 5 to 14 ; heterogeneity $\left.I^{2}=40 \%, P=0.17\right)$. In terms of access and engagement with treatment, although generally high, participants in early intervention

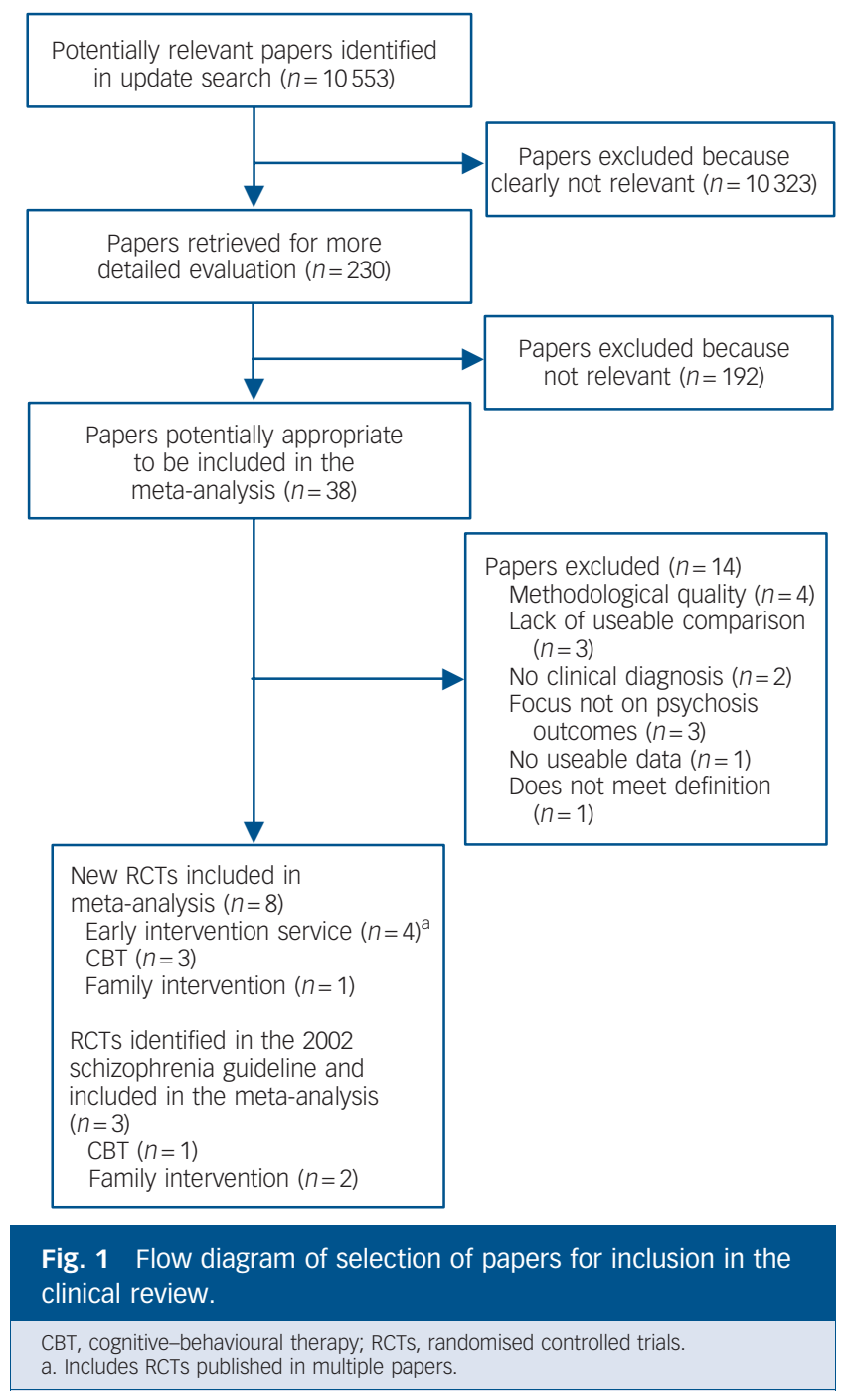




\begin{tabular}{|c|c|c|c|c|c|}
\hline Study (primary paper) & $\begin{array}{l}\text { Total } \\
\text { participants, } \\
n\end{array}$ & Treatment groups & $\begin{array}{l}\text { Duration and frequency } \\
\text { of treatment }\end{array}$ & $\begin{array}{l}\text { Standard } \\
\text { care comparison } \\
\text { group }\end{array}$ & $\begin{array}{l}\text { Outcomes extracted } \\
\text { for this review }\end{array}$ \\
\hline \multicolumn{6}{|c|}{ Early intervention services } \\
\hline $\mathrm{COAST}^{23}$ & 59 & $\begin{array}{l}\text { Early intervention service } \\
\text { including psychological } \\
\text { interventions as required }\end{array}$ & $\begin{array}{l}9 \text { months follow-up reported, } \\
\text { with service available } 7 \text { days } \\
\text { a week including nights }\end{array}$ & $\begin{array}{l}\text { Local available } \\
\text { CMHT services }\end{array}$ & $\begin{array}{l}\text { Leaving the study for any } \\
\text { reason, PANSS not extracted } \\
\text { as } n<10 \text { in comparison arm } \\
\text { at } 9 \text { months }\end{array}$ \\
\hline $\mathrm{LEO}^{11}$ & 144 & $\begin{array}{l}\text { Early intervention service } \\
\text { established on principles } \\
\text { of assertive outreach } \\
\text { including psychosocial } \\
\text { interventions }\end{array}$ & $\begin{array}{l}12 \text { and } 18 \text { months follow-up } \\
\text { reported, with extended hours } \\
\text { service including weekends }\end{array}$ & $\begin{array}{l}\text { Local available } \\
\text { CMHT services }\end{array}$ & $\begin{array}{l}\text { Leaving the study early, relapse, } \\
\text { hospital admission, remaining } \\
\text { in contact with services, } \\
\text { receiving psychosocial } \\
\text { interventions, positive } \\
\text { symptoms (PANSS), negative } \\
\text { symptoms (PANSS) }\end{array}$ \\
\hline OPUS $^{24}$ & 547 & $\begin{array}{l}\text { Early intervention service: } \\
\text { assertive community } \\
\text { treatment, family } \\
\text { intervention and social } \\
\text { skills training }\end{array}$ & $\begin{array}{l}\text { 2-year treatment duration, } \\
\text { with service available between } \\
8 \text { am and } 5 \mathrm{pm} \text { with a crisis } \\
\text { plan for each patient }\end{array}$ & $\begin{array}{l}\text { Services offered } \\
\text { by local community } \\
\text { mental health } \\
\text { centres }\end{array}$ & $\begin{array}{l}\text { Leaving the study early, hospital } \\
\text { admission, remaining in contact } \\
\text { with services, positive symptoms } \\
\text { (PANSS), negative symptoms } \\
\text { (PANSS) }\end{array}$ \\
\hline OTP ${ }^{12}$ & 50 & $\begin{array}{l}\text { Early intervention service: } \\
\text { integrated treatment with } \\
\text { structured psychological } \\
\text { interventions }\end{array}$ & $\begin{array}{l}\text { 2-year treatment duration, } \\
\text { with treatment session } \\
\text { provided weekly - monthly } \\
\text { over } 2 \text { years }\end{array}$ & $\begin{array}{l}\text { Regular clinic-based } \\
\text { services ( } 80 \% \text { from } \\
\text { hospital out-patient, } \\
20 \% \text { local community } \\
\text { general health } \\
\text { services) }\end{array}$ & $\begin{array}{l}\text { Leaving the study early, hospital } \\
\text { admission, relapse receiving } \\
\text { psychosocial interventions }\end{array}$ \\
\hline \multicolumn{6}{|c|}{ Cognitive-behavioural therapy } \\
\hline Jackson et al ${ }^{25}$ & 91 & $\begin{array}{l}\text { Individual CBT: cognitively } \\
\text { oriented psychotherapy }\end{array}$ & $\begin{array}{l}\text { 40-minute session weekly } \\
\text { or fortnightly for up to } \\
12 \text { months }\end{array}$ & $\begin{array}{l}\text { Early Psychosis } \\
\text { Prevention and } \\
\text { Intervention Centre } \\
\text { (EPPIC) }\end{array}$ & $\begin{array}{l}\text { Positive symptoms (BPRS), } \\
\text { negative symptoms (SANS), } \\
\text { hospital admission }\end{array}$ \\
\hline Lecomte et $a 1^{28}$ & 75 & $\begin{array}{l}\text { Group-based CBT tailored } \\
\text { to first-episode psychosis }\end{array}$ & $\begin{array}{l}24 \text { treatment sessions } \\
\text { delivered twice a week } \\
\text { for } 3 \text { months }\end{array}$ & $\begin{array}{l}\text { Local mental health } \\
\text { clinic or early inter- } \\
\text { vention programmes }\end{array}$ & $\begin{array}{l}\text { Positive symptoms (BPRS), } \\
\text { negative symptoms (BPRS) }\end{array}$ \\
\hline Lewis et $a^{26}$ & 203 & $\begin{array}{l}\text { Individual CBT: Study of } \\
\text { Cognitive Reality Alignment } \\
\text { Therapy in Early } \\
\text { Schizophrenia }\end{array}$ & $\begin{array}{l}15-20 \mathrm{~h} \text { within } 5 \text { weeks with } \\
\text { booster sessions at a further } \\
2 \text { weeks, } 1,2 \text { and } 3 \text { months }\end{array}$ & $\begin{array}{l}\text { Routine clinical care } \\
\text { from local mental } \\
\text { health units }\end{array}$ & $\begin{array}{l}\text { Positive symptoms (PANSS), } \\
\text { negative symptoms (PANSS), } \\
\text { relapse, hospital admission }\end{array}$ \\
\hline Wang et $a l^{27}$ & 251 & $\begin{array}{l}\text { Individual CBT offered } \\
\text { at recovery stage }\end{array}$ & $\begin{array}{l}\text { Six weekly } 40 \text { - to } 50 \text {-minute } \\
\text { sessions }\end{array}$ & $\begin{array}{l}\text { Hospital services } \\
\text { including clozapine } \\
\text { or risperidone }\end{array}$ & $\begin{array}{l}\text { Positive symptoms (PANSS), } \\
\text { negative symptoms (PANSS), } \\
\text { hospital admission }\end{array}$ \\
\hline \multicolumn{6}{|l|}{ Family intervention } \\
\hline Goldstein et al ${ }^{29}$ & 104 & $\begin{array}{l}\text { Family intervention: crisis } \\
\text { oriented, individually } \\
\text { delivered }\end{array}$ & $\begin{array}{l}\text { Six weekly intervention } \\
\text { sessions }\end{array}$ & $\begin{array}{l}\text { Standard treatment } \\
\text { with either low- } \\
\text { or high-dose } \\
\text { fluphenazine }\end{array}$ & $\begin{array}{l}\text { Relapse (end of treatment } \\
\text { and 6-month follow-up) }\end{array}$ \\
\hline Leavey et a $\beta^{30}$ & 106 & $\begin{array}{l}\text { Family intervention: } \\
\text { education and problem- } \\
\text { solving }\end{array}$ & Seven $1 \mathrm{~h}$ sessions & $\begin{array}{l}\text { Usual care from } \\
\text { psychiatric services } \\
\text { and CMHTs }\end{array}$ & $\begin{array}{l}\text { Hospital admission (end of } \\
\text { treatment) }\end{array}$ \\
\hline Zhang et $a^{\beta 1}$ & 78 & $\begin{array}{l}\text { Family intervention: group } \\
\text { and individual sessions } \\
\text { focused on education }\end{array}$ & $\begin{array}{l}18 \text { months with contact } \\
\text { every } 1-3 \text { months }\end{array}$ & $\begin{array}{l}\text { Standard hospital } \\
\text { out-patient services }\end{array}$ & $\begin{array}{l}\text { Hospital admission (end of } \\
\text { treatment) }\end{array}$ \\
\hline
\end{tabular}

services were more likely to remain in contact with the index mental health team $(91.4 \%$ v. $84.2 \%$; NNTB $=13,95 \%$ CI 4 to $\infty$; heterogeneity $\left.I^{2}=0 \%, P=0.79\right)$, and were twice as likely to receive a psychosocial intervention $(36.6 \%$ v. $14.0 \%$; NNTB $=5$, $95 \%$ CI 4 to 6 ; heterogeneity $\left.I^{2}=74 \%, P=0.02\right)$.

\section{Cognitive-behavioural therapy}

Four published trials of $\mathrm{CBT}^{25-28}$ were included in the review $(n=620)$. One paper ${ }^{27}$ published in Chinese but with an English abstract was translated subsequent to publication of the schizophrenia (update) guideline ${ }^{15}$ and included in this analysis.
Participants were recruited from a range of services which included early intervention services, community mental health clinics and in-patient psychiatric wards. In two trials, participants were exclusively in their first episode of psychosis. ${ }^{25,27}$ Another trial $^{26}$ additionally included participants who had been admitted for a second time, providing the episode occurred within 2 years of the first admission (17\% of their sample). The fourth trial ${ }^{28}$ included participants who had consulted a mental health professional for psychosis for the first time in the past 2 years. Cognitive-behavioural therapy was delivered individually in three out of the four trials, ${ }^{25-27}$ with a group-based approach in the fourth. ${ }^{28}$ Two of the interventions specifically adapted the CBT 


\begin{tabular}{|c|c|c|c|c|}
\hline Outcome & Time of data collection & $\begin{array}{c}\text { Trials, } \\
n\end{array}$ & $\begin{array}{l}\text { Participants, } n \text { : } \\
\text { treatment/control }\end{array}$ & $\begin{array}{l}\text { Summary effect estimate } \\
\qquad(95 \% \mathrm{Cl})\end{array}$ \\
\hline \multicolumn{5}{|l|}{ Early intervention service } \\
\hline Hospital admission ${ }^{11,12,24}$ & End of treatment & 3 & $342 / 280$ & $\mathrm{RR}=0.67$ (0.54 to 0.83$)$ \\
\hline Relapse (full or partial) $)^{11,12}$ & End of treatment & 2 & $91 / 81$ & $\mathrm{RR}=0.66(0.47$ to 0.94$)$ \\
\hline Positive symptoms (PANSS or SAPS) ${ }^{11,24}$ & End of treatment & 2 & $260 / 208$ & $\mathrm{SMD}=-0.21(-0.42$ to -0.01$)$ \\
\hline Negative symptoms (PANSS or SANS) ${ }^{11,24}$ & End of treatment & 2 & $260 / 208$ & $\mathrm{SMD}=-0.39(-0.57$ to -0.20$)$ \\
\hline Not receiving a psychological intervention ${ }^{11,12,24}$ & End of treatment & 3 & $344 / 286$ & $R R=0.67(0.46$ to 0.97$)$ \\
\hline Not in contact with index team ${ }^{11,24}$ & End of treatment & 2 & $314 / 266$ & $\mathrm{RR}=0.60$ (0.39 to 0.92$)$ \\
\hline Leaving the study early for any reason ${ }^{11,12,23,24}$ & End of treatment & 4 & $408 / 392$ & $\mathrm{RR}=0.71(0.53$ to 0.94$)$ \\
\hline \multicolumn{5}{|l|}{ Cognitive-behavioural therapy } \\
\hline Positive symptoms (BRPS, PANSS or SAPS) ${ }^{25-28}$ & End of treatment & 4 & $285 / 251$ & $\mathrm{SMD}=-0.05(-0.22$ to 0.12$)$ \\
\hline Positive symptoms ${ }^{26-28}$ & Up to 2 years follow-up & 3 & 233/209 & $\mathrm{SMD}=-0.60(-0.79$ to -0.41$)$ \\
\hline Negative symptoms (BRPS, PANSS or SAPS) $25,27,28$ & End of treatment & 3 & 207/191 & $\mathrm{SMD}=0.03(-0.17$ to 0.23$)$ \\
\hline Negative symptoms ${ }^{26-28}$ & Up to 2 years follow-up & 3 & 233/209 & $\mathrm{SMD}=-0.45(-0.80$ to -0.09$)$ \\
\hline Relapse ${ }^{26,27}$ & Up to 2 years follow-up & 2 & $227 / 227$ & $\mathrm{RR}=0.67(0.24$ to 1.85$)$ \\
\hline Hospital admission ${ }^{25,26}$ & Up to 2 years follow-up & 2 & $146 / 148$ & $\mathrm{RR}=1.01(0.76$ to 1.35$)$ \\
\hline \multicolumn{5}{|l|}{ Family intervention } \\
\hline Relapse 29 & End of treatment & 1 & $52 / 52$ & $\mathrm{RR}=0.58(0.25$ to 1.36$)$ \\
\hline Relapse $^{29}$ & Up to 2 years follow-up & 1 & $52 / 52$ & $\mathrm{RR}=0.75$ (0.39 to 1.43$)$ \\
\hline Hospital admission 30,31 & End of treatment & 2 & $99 / 90$ & $\mathrm{RR}=0.51(0.24$ to 1.10$)$ \\
\hline Hospital admission and relapse (combined) ${ }^{29-31}$ & End of treatment & 3 & $151 / 142$ & $\mathrm{RR}=0.50(0.32$ to 0.80$)$ \\
\hline
\end{tabular}

approach for early psychosis, ${ }^{25,28}$ with the remaining two interventions targeting positive symptoms ${ }^{26}$ and insight building. ${ }^{27}$ The frequency of sessions and the duration of treatment varied across trials, with the total duration ranging from 5 weeks (plus booster sessions) ${ }^{26}$ to 1 year. $^{25}$

At up to 2 years post-treatment follow-up, when compared with standard care alone, CBT significantly reduced mean positive symptoms with a pooled SMD of -0.60 ( $95 \%$ CI -0.79 to -0.41 ; heterogeneity $\left.I^{2}=0 \%, P=0.44\right)$ and mean negative symptoms with a pooled SMD of -0.45 ( $95 \% \mathrm{CI}-0.80$ to -0.09 ; heterogeneity $\left.I^{2}=62 \%, P=0.07\right)$. These benefits were not evident at the end of treatment in terms of both positive (SMD $=-0.05,95 \% \mathrm{CI}$ -0.22 to 0.12 ; heterogeneity $\left.I^{2}=0 \%, P=0.92\right)$ and negative symptoms ( $\mathrm{SMD}=0.03,95 \% \mathrm{CI}-0.17$ to 0.23 ; heterogeneity $I^{2}=0 \%, P=0.41$ ), or relapse within the 2 -year follow-up period (27.8\% v. 32.2\%, $P=0.44$; heterogeneity $I=79 \%, P=0.03)$. Rates of hospital admission up to 2 years follow-up also failed to demonstrate any additional benefit for CBT compared with standard care $\left(38.4 \%\right.$ v. $38.5 \%, P=0.94$; heterogeneity $\left.I^{2}=0 \%, P=0.36\right)$.

\section{Family intervention}

Three trials $(n=288)$ assessing family intervention in early psychosis were included in the review. ${ }^{29-31}$ Participants were recruited from psychiatric services, including in-patient units, and were either first or second admissions, ${ }^{29,31}$ or had made first contact with services within the past 6 months. ${ }^{30}$ Two trials ${ }^{29,30}$ included the individual with psychosis in the family sessions, whereas in Zhang et $a l^{31}$ the majority of family sessions did not include the patient. The interventions delivered in each trial included an element of psychoeducation and problem-solving, with crisis management also evident in one trial. ${ }^{29}$ Interventions varied in their mode of delivering, with two trials ${ }^{29,30}$ utilising an individual family approach and the remaining trial combining individual and group-based family sessions. Only one trial ${ }^{29}$ reported relapse and a further two trials ${ }^{30,31}$ reported hospital admission; these outcomes were combined to increase statistical power.

The combined analysis indicated that at the end of treatment, participants receiving family intervention were less likely to relapse or be admitted to hospital compared with those receiving standard care $(14.5 \%$ v. $28.9 \%$; NNTB $=7,95 \%$ CI 4 to 20 ; heterogeneity $I^{2}=0 \%, P=0.40$ ). At up to 2 years follow-up, one study ${ }^{29}$ reported a numerically lower risk of relapse $(23.1 \%$ v. $30.8 \%$, $P=0.38$ ), although this was not statistically significant. None of the included family intervention trials provided data on mean positive and negative symptoms.

\section{Discussion}

\section{Main findings}

For people with early psychosis, in four trials of early intervention services, four trials of CBT, and three trials of family intervention, meta-analysis demonstrated advantages over standard care. By the end of treatment, early intervention services produced clinically important reductions in the risk of both relapse and hospital admission. In addition, small effects favouring early intervention services were shown in terms of reduced symptom severity and improved access to and engagement with treatment (including psychological therapies). Family intervention also produced clinically important reductions in the risk of relapse and hospital admission when compared with standard care. In the 2 years following the intervention, medium effects favouring CBT were demonstrated in terms of reduced positive and negative symptom severity. We found no data on the effect of family intervention on symptoms and insufficient evidence to reach a conclusion about the impact of CBT on relapse or hospital admission.

\section{Early intervention services}

Compared with a previous review of early interventions in psychosis, ${ }^{13}$ our meta-analysis found stronger evidence to support the effectiveness of early intervention services overall. The earlier review included fewer trials that specifically focused on servicelevel interventions delivered during the 'critical period' following onset of psychosis. Furthermore, although the previous review included both discrete psychosocial and multicomponent service-level interventions, there was a lack of comparable trials for any conclusions to be drawn. Our findings do, however, 
substantiate those previously reported in a narrative review of randomised and non-randomised studies by Penn and colleagues, ${ }^{14}$ who concluded that early interventions had beneficial effects across a range of domains, although further investigation was needed to establish the robustness of these findings. ${ }^{14}$ Our review attempts to overcome these limitations and provides the first meta-analytic evidence indicating that both early intervention services and discrete psychological interventions improve outcomes for early psychosis.

In the present review, the early intervention services provided in all of the trials included the provision of psychosocial interventions, pharmacological treatment and some form of case management involving smaller case-loads (1:10) and an assertive approach to treatment. All of the components were tailored to meet the needs of the individual patient and offered at the earliest opportunity. These elements were not present in treatment as usual, although an assertive approach to treatment is so common that it cannot be specifically excluded. The psychological interventions used in the included trials were CBT and either family intervention ${ }^{12,23,24}$ or family counselling. ${ }^{11}$ It is possible that the reduced case-loads and more appropriate use of pharmacological interventions within early intervention services may account for some of the clinical and statistically important improvements demonstrated. Although further research is needed to investigate the beneficial contributions of these features of early intervention, given the positive effects of CBT and family intervention when delivered as discrete interventions for people with early psychosis, it is just as likely that these two psychosocial interventions have contributed to some of the benefits of early intervention services in this review.

Gleeson and colleagues ${ }^{32}$ recently demonstrated that the addition of a cognitive-behavioural and family therapy-based relapse prevention programme to an early intervention service for individuals in remission from a first episode of psychosis was more likely to prevent or significantly delay a second episode when compared with an early intervention service alone. In this trial the early intervention service alone included only family psychoeducation and peer support. This study provides some evidence to support our hypothesis: that an important part of the overall effectiveness of the early intervention teams included in our meta-analysis derives from the inclusion of two evidencebased psychological interventions, namely, CBT and family intervention. In our review we have shown that the likelihood of a service user receiving a psychosocial intervention in an early intervention team is double that found in a community mental health team.

\section{Limitations}

One limitation of the present review is the paucity of trials included in each meta-analysis. We excluded trials focusing on high-risk groups or prevention of psychosis because of the possible ethical implications of targeting interventions at these individuals. ${ }^{5}$ Another limitation is the variability in long-term follow-up measures available in different trials making some comparisons difficult. Only one trial of an early intervention service provided long-term data (up to 5 years post-randomisation), ${ }^{24}$ whereas all four trials of $\mathrm{CBT}^{25-28}$ and one of family intervention ${ }^{29}$ included long-term follow-up measures. Therefore, it remains to be determined whether the effects of early intervention services are sustained.

\section{Psychological interventions}

Despite the limitations, our findings regarding the efficacy of CBT and family intervention are consistent with, and reflect, the wider evidence base found in the treatment and management of later psychotic episodes. The updated edition of the schizophrenia guideline ${ }^{15}$ recommends that both interventions should be offered to people experiencing an acute episode of schizophrenia and for promoting recovery in those with established schizophrenia.

The evidence presented here suggests that CBT for early psychosis has longer-term benefits in terms of reducing symptom severity. Consistent with the wider evidence base for CBT for established psychosis, the present review failed to find any evidence that CBT reduced relapse rates in early psychosis, which suggests that the main benefits of this intervention are likely to be a reduction in symptoms and distress in early and established psychosis. This finding confirms a recent review assessing both RCTs and non-randomised studies of CBT in first-episode psychosis, which also failed to demonstrate positive effects on relapse and readmission. ${ }^{33}$

Although the number of RCTs for family interventions for early psychosis was limited in our review, the evidence is consistent with the larger body of evidence for the role of family interventions in established schizophrenia, in that family intervention reduced combined hospital admission and relapse rates. The review conducted for the updated edition of the schizophrenia guideline $\mathrm{e}^{15}$ also found robust evidence for the efficacy of family intervention in established schizophrenia in reducing symptoms at the end of treatment. However, in the present review, none of the included trials reported measures that allowed us to assess this in the context of early psychosis. It is, therefore, anticipated that family intervention in first-episode psychosis may also reduce symptom levels.

\section{Critical period}

The studies included in the present review did not provide any data relating to DUP, as all papers focused on people with an agreed diagnosis, not on populations at high risk of becoming psychotic and receiving a diagnosis. A number of other reviews assessing DUP as a predictor have indicated that longer DUP is subsequently associated with poorer outcomes, including reduced adherence to $\mathrm{CBT}^{34}$ altered response to antipsychotic medications, ${ }^{35}$ poorer social functioning ${ }^{36}$ and increased levels of disability. ${ }^{37}$ There is some suggestion from studies assessing the impact of early intervention programmes on high-risk and ultra-high-risk populations that education and awareness of psychosis may significantly reduce DUP. ${ }^{38}$ However, further research is needed to clarify issues surrounding DUP. ${ }^{39}$

The present review focused on the first 3-5 years following the onset of illness. This period has been defined as a critical period, when many of the psychological, clinical and social deteriorations associated with psychosis might occur, ${ }^{5,7,40}$ and when interventions might potentially have their greatest positive impact on prognosis. ${ }^{5,6}$ Although the current evidence to support this idea is limited, intervening at the earliest possible opportunity makes both practical and ethical sense, and hope remains that such intervention might reduce subsequent symptom severity, loss of functioning and other negative consequences of psychosis such as social exclusion. ${ }^{41}$ Intervening early may also help to reduce the adverse social and societal consequences of the disorder for both individuals and their family and carers. However, it can also be argued that providing excellent care and access to a range of appropriate and effective psychological, pharmacological and vocational interventions should be available at any stage of psychosis. ${ }^{42,43}$

\section{Implications}

On balance, the evidence reviewed here suggests that early intervention services are an effective way of delivering care for people with early psychosis and can reduce hospital admission, 
relapse rates and symptom severity, while improving access to and engagement with a range of treatments. The characteristics of these early intervention services include the provision of multimodal psychosocial interventions, pharmacotherapy, and some form of case management with lower case-loads and an assertive approach to treatment, all within the context of intervening as early as possible. Our review also suggests that providing evidence-based psychological interventions as part of a comprehensive early intervention service may contribute to improving outcomes for people with early psychosis. It is important that these psychological interventions have been shown rather more robustly to be effective for people with established schizophrenia. This raises the possibility that comprehensive services comparable to those described here as early intervention services, which include a full range of evidence-based psychological interventions, should be considered for people with established psychosis.

Victoria Bird, BSc, National Collaborating Centre for Mental Health, Royal College of Psychiatrists' Research and Training Unit, London; Preethi Premkumar, MPhil,

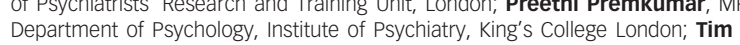
Kendall, FRCPsych, Royal College of Psychiatrists' Research and Training Unit, London, Craig Whittington, PhD, National Collaborating Centre for Mental Health, Centre for Outcomes Research and Effectiveness, Research Department of Clinical, Educational \& Health Psychology, University College London; Jonathan Mitchell, MRCPsych, Sheffield Health and Social Care Trust, Sheffield; Elizabeth Kuipers, PhD, FBPSS, AccSS, Department of Psychology, Institute of Psychiatry, King's College London, UK

Correspondence: V. Bird, National Collaborating Centre for Mental Health, Royal College of Psychiatrists' Research and Training Unit, Standon House, 21 Mansell Street, London E1 8AA, UK. Email: vbird@cru.rcpsych.ac.uk

First received 20 Jan 2009, final revision 3 Jul 2010, accepted 22 Jul 2010

\section{Funding}

T.K. receives, as director of the National Collaborating Centre for Mental Health (NCCMH) approximately $f 1.44$ million per year from NICE to develop clinical guidelines. T.K. and C.W were paid by the NCCMH to undertake the development of both the original and updated edition of the schizophrenia guideline.,, 15 V.B. and I.M. Were paid by the NCCMH to undertake the development of the updated edition of the schizophrenia guideline. ${ }^{15} \mathrm{~T}$.K. was chair of the original NICE schizophrenia guideline ${ }^{9}$ and E.K. was chair of the updated edition. ${ }^{15}$ P.P. is supported by a Wellcome Trust Senior Research Fellowship to Veena Kumari (067427/z/02/z). The Biomedical Research Centre for Mental Health at the Institute of Psychiatry, King's College London and the South London and Maudsley NHS Foundation Trust funds some clinical sessions for E.K.

\section{Acknowledgements}

We thank other members of the Guideline Development Group of the updated edition of the schizophrenia guideline ${ }^{15}$ and Ms Sarah Stockton for creating the search strategies and conducting the database searches. We also thank Dr Adegboyega Sapara for independently extracting the data for the CBT section of the review.

\section{References}

1 Harrigan S, McGorry P, Krstev H. Does treatment delay in first-episode psychosis really matter? Psychol Med 2003; 33: 97-110.

2 Harrison G, Hopper K, Craig T, Laska E, Siegel C, Wanderling J, et al. Recovery from psychotic illness: a 15- and 25-year international follow-up study. Br J Psychiatry 2001; 178: 506-17.

3 Linszen $D$, Dingemans $P$, Lenoir $M$. Early intervention and a five-year followup in young adults with a short duration of untreated psychosis: ethical implications. Schizophr Res 2001; 51: 55-61.

4 Bottlender $\mathrm{R}$, Sato $\mathrm{T}$, Jager $\mathrm{M}$. The impact of the duration of untreated psychosis prior to first psychiatric admission on the 15-year outcome in schizophrenia. Schizophr Res 2009; 62: 37-44.

5 Birchwood M, McGorry $\mathrm{P}$, Jackson H. Early intervention in schizophrenia. Br J Psychiatry 1997; 170: 2-5.

6 Joseph $\mathrm{R}$, Birchwood M. The national policy reforms for mental health services and the story of early intervention services in the United Kingdom. J Psychiatry Neurosci 2005; 30: 362-5.
7 Lieberman JA, Fenton WS. Delayed detection of psychosis: causes, consequences and effect on public health. Am J Psychiatry 2000; 157 1727-30.

8 Department of Health. National Service Framework for Mental Health: Modern Standards and Service Models. Department of Health, 1999.

9 National Institute for Clinical Excellence. Schizophrenia: Core Interventions in the Treatment and Management of Schizophrenia in Primary and Secondary Care (CG1). National Institute for Clinical Excellence, 2002.

10 Singh SP, Wright C, Burns T, Joyce E, Barnes TRE. Developing early intervention services in the NHS: a survey to guide workforce and training needs. Psychiatr Bull 2003; 27: 254-8.

11 Craig T, Garety P, Power P, Rahaman N, Colbert S, Fornells-Ambrojo M, et al. The Lambeth Early Onset (LEO) Team: randomised controlled trial of the effectiveness of specialised care for early psychosis. BMJ 2004; 329 : 1067-71.

12 Grawe RW, Falloon IR, Widen JH, Skogvoll E. Two years of continued early treatment for recent-onset schizophrenia: a randomised controlled study. Acta Psychiatr Scand 2006; 114: 328-36.

13 Marshall M, Rathbone J. Early Intervention for psychosis. Cochrane Database Syst Rev 2006; 4: CD004718.

14 Penn DL, Waldheter EJ, Perkins DO, Mueser KT, Lierberman JA. Psychosocial treatment for first-episode psychosis: a research update. Am J Psychiatry 2005; 162: 2220-32.

15 National Collaborating Centre for Mental Health. Schizophrenia: Core Interventions in the Treatment and Management of Schizophrenia in Adults in Primary and Secondary Care (Clinical Guideline CG82). National Institute for Health and Clinical Excellence, 2009.

16 Scottish Intercollegiate Guidelines Network. SIGN 50: A Guideline Developer's Handbook. SIGN, 2001.

17 Kay SR, Fiszbein A, Opler LA. The Positive and Negative Syndrome Scale (PANSS) for schizophrenia. Schizophr Bull 1987; 13: 261-76.

18 Ventura J, Lukoff KH, Neuchterlein KH, Liberman RP, Green MF, shaner A. Manual for the Expanded Brief Psychiatric Rating Scale. Int J Methods Psychiatr Res 1993; 3: 227-44.

19 Andreasen NC. The Scale for the Assessment of Positive Symptoms (SAPS) University of lowa, 1984.

20 Andreasen NC. The Scale for the Assessment of Negative Symptoms (SANS). University of lowa, 1984.

21 Altman DG. Confidence intervals for the number needed to treat. BMJ 1998: 317: 1309-12.

22 Schmidt FL, Oh IS, Hayes TL. Fixed- versus random-effects models in meta-analysis: model properties and an empirical comparison of differences in results. Br J Math Stat Psychol 2009; 62: 97-128.

23 Kuipers E, Holloway F, Rabe-Hesketh S, Tennakoon L. An RCT of early intervention in psychosis: Croydon Outreach and Assertive Support Team (COAST). Soc Psychiatry Psychiatr Epidemiol 2004; 39: 358-63.

24 Petersen $L$, Jeppesen $P$, Thorup A, Abel MB, Ohlenschlaeger J, Christensen $\mathrm{TO}$, et al. A randomised multicentre trial of integrated versus standard treatment for patients with a first episode of psychotic illness. BMJ 2005; 331: $602-8$.

25 Jackson H, McGorry P, Edwards J, Hulbert C, Henry L, Harrigan S, et al. A controlled trial of cognitively oriented psychotherapy for early psychosis (COPE) with four-year follow-up readmission data. Psychol Med 2005; 35 1295-306.

26 Lewis S, Tarrier N, Haddock G, Bentall R, Kinderman P, Kingdon D, et al. Randomised controlled trial of cognitive-behavioural therapy in early schizophrenia: acute-phase outcomes. Br J Psychiatry 2002; 181 (suppl 43): s91-7.

27 Wang $C$, Li Y, Zhao Z, Pan M, Feng Y, Sun F, et al. Controlled study on longterm effect of cognitive behavior intervention on first episode schizophrenia. Chinese Ment Health J 2003; 17: 200-2.

28 Lecomte $\mathrm{T}$, Leclerc $\mathrm{C}$, Corbière $\mathrm{M}$, Wykes $\mathrm{T}$, Wallace $\mathrm{CJ}$, Spidel A. Group cognitive behavior therapy or social skills training for individuals with a recent onset of psychosis? Results of a randomized controlled trial. J Nerv Ment Dis 2009; 196: 866-75.

29 Goldstein MJ, Rodnick EH, Evans JR, May PRA, Steinberg MR. Drug and family therapy in the aftercare of acute schizophrenics. Arch Gen Psychiatry 1978; 35: 1169-77.

30 Leavey G, Gulamhussein S, Papadopoulous C, Johnson-Sabine E, Blizard B, King M. A randomized controlled trial of a brief intervention for families of patients with a first episode of psychosis. Psychol Med 2004; 34: 423-31.

31 Zhang M, Wang M, Li J, Phillips MR. Randomised-control trial of family intervention for 78 first-episode male schizophrenic patients. An 18-month study in Suzhou, Jiangsu. Br J Psychiatry Suppl 1994; 165 (suppl 24): 96-102. 
32 Gleeson JFM, Cotton SM, Alvarez-Jimenez D, Wade D, Gee D, Crisp K, et al A randomized controlled trial of relapse prevention for first-episode psychosis patients. J Clin Psychiatry 2009; 70: 477-86.

33 Morrison AP. Cognitive behaviour therapy for first episode psychosis: good for nothing or fit for purpose? Psychosis 2009; 1: 103-12.

34 Álvarez-Jiménez M, Gleeson JF, Cotton S, Wade D, Gee D, Pearce T, et al. Predictors of adherence to cognitive-behavioural therapy in first episode psychosis. Can J Psychiatry 2009; 54: 710-8.

35 Perkins DO, Gu H, Boteva K, Lieberman JA. Relationship between duration of untreated psychosis and outcome in first-episode schizophrenia: a critical review and meta-analysis. Am J Psychiatry 2005; 162: 1785-804.

36 Barnes TRE, Leeson VC, Mutsatsa SH, Watt HC, Hutton SB, Joyce EM. Duration of untreated psychosis and social function: 1-year follow-up study of first-episode schizophrenia. Br J Psychiatr 2008; 193: 203-9.

37 Farooq $\mathrm{S}$, Large $\mathrm{M}$, Nielssen $\mathrm{O}$, Waheed $\mathrm{W}$. the relationship between the duration of untreated psychosis and outcome in low-and-middle income countries: a systematic review and meta analysis. Schizophr Res 2009; 109: $15-23$.

38 Joa I, Johannessen JO, Auestad B, Friis S, McGlashan T, Melle I, et al. The key to reducing duration of untreated psychosis: information campaigns. Schizophr Bull 2008; 34: 466-72.

39 McGorry PD. Evaluating the importance of reducing the duration of untreated psychosis. Aust N Z J Psychiatry 2000; 34: S145-9.

40 Birchwood M, Iqbal Z, Chadwick P, Trower P. Cognitive approach to depression and suicidal thinking in psychosis. I. Ontogeny of post-psychotic depression. Br J Psychiatry 2000; 177: 516-28.

41 Thornicroft G. Tackling discrimination. Ment Health Today 2006; Jun: 26-9.

42 Kuipers $\mathrm{E}$. The case for early, middle and late intervention in psychosis. World Psychiatry 2008; 7: 158-9.

43 van Os J, Kapur S. Schizophrenia. Lancet 374: 635-45.

\section{poems \\ by doctors}

\section{Strategy}

\section{Peter Wells}

Love was at a premium -

Jane ran out of supplies.

Father a miner, his life stained by cold dust,

his chest a box of birds,

let go his last persecutory breath.

Mum had three daughters to keep,

all got the message:

love is a ration book.

Jane, the youngest, had least time

for what was left of the crust;

a starveling in love

she sickened for it.

When the strategy was rumbled

she risked the lot

and slit her wrists

In and out of hospital

a lifetime career;

the only way to keep going

and to save Mum.

She hid behind the curtains

when she won the ward prize for a cake.

she could not explain herself.

Paint became her arbiter

picture after picture -

they did not need words.

At long last, she found words:

'I got into hospital by pretending to be sick,

I got home by pretending to be sane'. 